
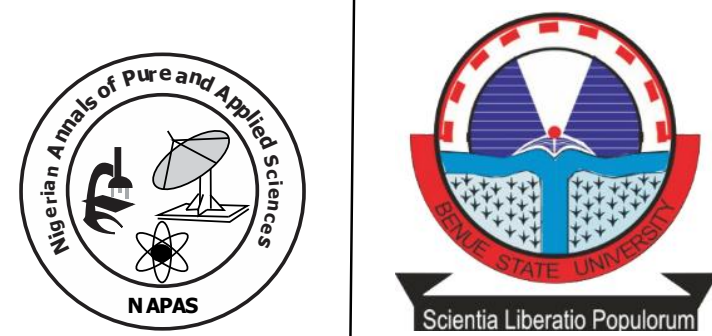

\title{
An Empirical Investigation of the Random Walk Hypothesis in the Nigerian Stock Market
}

\author{
Kuhe, D.A. and Akor, J. \\ Department of Mathematics/Statistics/Computer Science, Federal \\ University of Agriculture, Makurdi, Benue State-Nigeria. \\ Corresponding Author: davidkuhe@gmail.com
}

doi: https//doi.org/10.46912/napas.229

\begin{abstract}
The Random Walk Hypothesis (RWH) states that stock prices move randomly in the stock market without following any regular or particular pattern and as such historical information contained in the past prices of stocks cannot be used to predict current or future stock prices. Hence, stock prices are unpredictable and that investors cannot usurp any available information in the market to manipulate the market and make abnormal profits. This study empirically examines the random walk hypothesis in the Nigerian stock market using the daily quotations of the Nigerian stock exchange from $2^{\text {nd }}$ January, 1998 to $31^{\text {st }}$ December, 2019. The study employs Augmented Dickey-Fuller unit root test, the random walk model, Ljung-Box Q-statistic test for serial dependence, runs test of randomness, and the robust variance ratio test as methods of analyses. The result of the study rejected the null hypotheses of a unit root and random walk in the stock returns. The null hypothesis of no serial correlation in the residuals of stock returns was also rejected indicating the presence of serial correlation/autocorrelation in the residual series. The result of the runs test rejected the null hypothesis of randomness in the Nigerian stock returns. The results of the variance ratio test under homoskedasticity and heteroskedasticity assumptions both strongly rejected the null hypothesis of a random walk for both joint tests and test of individual periods. Based on the results of the four tests applied in this study, it is concluded that the Nigerian daily stock returns under the period of investigation do not follow a random walk and hence the null hypothesis of a random walk is rejected. The results of the study further revealed that the Nigerian stock market is weak-form inefficient indicating that prices in the Nigerian stock market are predictable, dependable, consistently mispriced, inflated, liable to arbitraging and left unprotected to speculations and market manipulations. The study provided some policy recommendations.
\end{abstract}

Keywords: Efficiency Market, Randomness, Serial Correlation, Stock Prices, Unit Root, Nigeria. 


\section{Introduction}

Stock markets are mechanisms for trading on existing securities that represent the value of shares and bond of firms and government institutions and are known for playing crucial functions in the financial system including mobilization of savings from both private and public sector and channeling the savings to productive investment ventures, protecting investments from fraudulent and shady deals, facilitating transactions in government securities and advertising investors, industries and government dealings with securities and serves as a medium of information exchange between investors and industries (Olabisi et al., 2017). Stock markets also mobilize resources with capital formation which helps in reducing illiquidity risk and promoting investment opportunities. More importantly, the stock market creates a platform for participants to buy and sell existing stock; and also, raise new issues (Abina, 2019). By this, the stock market performs a very germane function of resources allocation.

For proper allocation of financial resources, the stock market needs to be efficient (Afrafayia, 2018). The market is said to be efficient when current prices of stock traded in the market reflect all available information (Aliyev, 2019). Efficiency of a stock market implies that prices of securities are solely determined by the market forces of demand and supply, based on available information. The effectiveness of the market lies on the investors' behaviour and investment pattern, influenced by information and competition (Pervez et al., 2018). This implies that all investors deal with the same information, movements in the securities prices in an efficient market are unpredictable and the information entering the market is absorbed swiftly by all participants, thus no investor can be more advantageous to make unfair gain in the market. Fama (1970) in his Efficient Market Hypothesis $(\mathrm{EMH})$ put forward that an efficient market refers to a stock market where expected inflows cannot be exploited by trading in a particular pattern. Efficient market hypothesis relates to the notion of random walk, which portrays staggered movement or changes in prices of securities such that the current prices cannot be predicted from previous records or prices. The opinion of random walk is that the successive price changes are independent and identically distributed random variables, which indicate that the series of price changes has no relationship; and the past cannot be employed to predict the future, as the prices are devoid of any meaningful trend (Fama, 1970).

Adelegan (2003) classified stock market efficiency into operational, allocation and pricing efficiency. Operational efficiency implies that all transactions in securities are carried out instantly, correctly, and at a low cost. The allocation efficiency refers to mechanism which allocates scarce resources to where they can be most productive. The highest bidder is allowed to have the investment opportunity which implies that most efficient use of scarce resource is ensured in the economy. The pricing efficiency connotes that an investor can only expect to earn riskadjusted returns from an investment as prices move instantaneous and in an unbiased manner to any news.

Fama (1970) categorized the Efficient Market Hypothesis (EMH) into three levels based on the set of available information arriving to the market as, the weak form EMH, the Semi strong form EMH, and the Strong form EMH. In the weak form, only the past information on prices of shares are reflected, in the semi strong form, it reflects all publicly available information in security prices, including the past security prices and the announcements of dividend payments, changes in capital structure, change of management and other event; while the strong form captures all information be it external, internal and even unannounced.

The random walk hypothesis (RWH) asserts that since stock prices move randomly without following any definite pattern, it is useless to select stocks based on information about recent trends in stock prices. The fact that the price of stocks has risen for the past few days will give no useful information as what today's or tomorrows price will be. Thus potential investors who follow the price trend in order to forecast price or determine when to buy and sell the stock are wasting their time. There are no regularities or patterns in security prices that repeat themselves over time as to predict future stock prices from past prices. Each price change that occurs in the market is independent of the previous price changes and the price movement behaves randomly. When the stock prices of a stock market follow a random walk, the market is said to be weak-form efficient (Adelegan, 2003). 
Many studies have been conducted on the random walk hypothesis. However, the focus has been on the well-established and developed stock markets leaving behind the developing stock markets, such as the African stock markets. It is believed that, in developing stock markets, stock prices follow a random walk and the markets are weak-form inefficiency, however, this idea needs to be empirically re-examined, re-investigated, reassessed and documented and therefore much is desired to be studied and documented from these African stock markets. This study therefore seeks to examine the random walk hypothesis and by implication the efficiency market hypothesis in the Nigerian stock market (NSM) using daily closing all share index of the Nigerian Stock Exchange (NSE).

The aim of this study is to empirically examine the random walk hypothesis in the Nigerian stock market. The specific objectives of the study are (i) to examine the unit root and stationarity properties of stock return series; (ii) to test for serial dependence/independence of successive price movements in the Nigerian stock return series; (iii) to test for randomness and pattern of stock price movement in the Nigerian stock market. The rest of the paper is organized as follows: Section 2 reviews some relevant literature on the subject matter, Section 3 presents materials and methods, Section 4 focuses on results presentation and discussion while Section 5 hinges on the concluding remarks.

\section{Literature Review}

There is abundance of empirical literature relating to the random walk theory and efficient market hypothesis. Empirical studies investigated the random walk behaviour of stock returns across the globe. Some of these researches are interested in regional equity markets, others have concentrated on the international stock markets, while others are interested in individual stock markets to provide evidence on the random walk and efficient market theories.

Abushammaala (2011) studied the weakform efficiency of Palestine Exchange using daily prices of General index and Al-Qids index for the period covering January, 2007 to December, 2010. The findings from Phillips \& Perron (PP) test showed that the return series of Palestine Exchange (PEX) did not behave randomly and therefore the market was a weak form inefficient market. In a similar vein, Nisar and Hanif (2012) examined the weak-form efficiency hypothesis on the four major stock exchanges of South Asia (India, Pakistan, Bangladesh and Sri Lanka) using monthly, weekly and daily historical index for a period of 14 years. The results of variance ratio test under homoskedasticity and heteroskedsticity assumptions revealed that none of the four major stock markets of South Asia followed random walk and hence the markets were declared weak form inefficient for the period the study. Sania and Rizwan (2014) tested the weak form efficiency of capital markets in Pakistan using daily data of Karachi Stock Exchange (KSE-100 index) from 2009 to 2010 and employed the Augmented Dickey Fuller unit root tests as one of the statistical tests. They found that there was a positive correlation in KSE-100 index and therefore based on the results of ADF test, they concluded that the KSE was not behaving in random fashion and hence it was not a weak form efficient market.

McKerrow (2013) examined the random walk hypothesis in frontier stocks markets of Botswana, Ivory coast, Ghana, Mauritius and Namibia using monthly time series data for 16 years and employed naïve random walk, the runs test and the multiple variance ratio test. The findings of the study resulted into mixed conclusion, while the analysis using runs test revealed a rejection of the random walk hypothesis for the markets of Namibia and Ivory Coast and acceptance of random walk hypothesis for the markets of Botswana, Ghana and Mauritius. Owido et al. (2013) employed both non-parametric methods and GARCH models to check for randomness and independence of stock market returns at the Nairobi Securities Exchange. Results showed that daily returns were non-random and the GARCH analysis showed that the current returns were dependent on the returns of the previous 3 days. The $\operatorname{GARCH}(3,1)$ model showed that returns on a particular day would be determined by the mean returns plus a white noise error term which would vary by $25.3 \%$ of return on day $t-1,9.5 \%$ of return on day $t-2$ and $12.05 \%$ of returns on day $t-3$ at 0.05 level of significance. This signified market inefficiency of the weak form.

Izz Eddien (2014) conducted a study to test the efficiency of the Amman stock market (ASE) returns at the weak-form, by using daily 
observations for the Amman Stock Exchange. Parametric and nonparametric tests were utilized for examining the randomness of stock prices for ASE. The Jarque-Bera test showed that the daily returns of the ASE were not normally distributed, and the runs tests both detected that the daily returns were inefficient at the weak form. In addition, the Augmented Dickey-Fuller (ADF) unit root test and Phillips-Peron (PP) unit root test suggested the weak-form inefficiency in the return series. The study therefore concluded that the ASE stock market rejected the random walk hypothesis and was inefficient at the weak form level. Abbas (2014) examined whether daily stock returns on Damascus Securities Exchange follow a random walk for the period of 2009 to 2014. The study applied two parametric tests namely serialcorrelation test and variance ratio test, and two non -parametric tests, i.e. runs test and Brock, Dechert and Scheinkman (BDS) test. It was found that daily returns do not confirm to a random walk during the period under examination. This result was consistent in both parametric and nonparametric tests. The study concluded that price returns might be predictable; hence, it was possible for investors to earn higher return than average by using historical successive prices.

Kumar and Kumar (2015) in a study on the Indian stock market inquired whether the market was efficient thus following a random walk using daily closing prices of the NSE Midcap 50 Index over the duration, $15^{\text {th }}$ September 2010 to $28^{\text {th }}$ November 2014. Existence of the random walk was examined through auto-correlation, Qstatistics and the runs tests. The results showed that the Indian stock market was not efficient in the weak-form during the testing period indicating that the stock prices in India did not reflect all the information in the past stock prices and abnormal returns could be achieved by investors through exploiting the market inefficiency. Adigwe et al. (2017) examined whether some selected African stock exchanges provided evidence of weak form efficiency in the recent time period of January 2013 to December 2015. The study covered 13 out of the 28 stock exchanges in Africa, representing 38 nations' capital markets. The Jarque-Bera statistics test of normality and Augmented Dickey-Fuller test of stationarity for stock market efficiency were employed. Findings from the result indicated that (1) African stock market prices followed normal distribution; (2) succeeding price changes were not independent and move randomly in African stock markets. The study concluded that African stock markets were weak form inefficient within the period under study. The study therefore recommended that addressing trading frictions; promoting timely disclosure and dissemination of information to investors on the performance of listed companies; and strengthening regulatory oversight were the key elements of a strategy aimed at improving the efficiency of the capital markets in Africa.

Izz Eddien (2016) empirically examined the EMH at the weak form level of Amman stock Exchange (ASE) by using daily observations for the period spanned from 2000 to 2013. The study employed some econometric procedures such as serial correlation test, unit root and runs tests for testing the randomness of stock prices for ASE. The results of serial correlation rejected the existence of random walks in daily returns of the ASE, and the unit root tests also concluded that the return series of ASE were stationary and inefficient at the weak-level. Also the runs tests verified that the stock returns series on ASE were not random, and the final conclusion was that the ASE was inefficient at the weak form level. Maximillian and Gwahula (2018) examined empirically the efficient market hypothesis in the Dar es Salaam Stock Exchange (DSE) using the daily closing stock prices of the market index from January 2009 to March 2015. The study used four different statistical tests: serial correlation test, the Ljung-Box Q-statistic test, unit root tests, non-parametric runs test and the variance ratio test. The results of all the four statistical tests employed showed that the daily returns series did not behave randomly for the sample period investigated and hence it was concluded that DSE was not a weak form efficient market.

In Nigeria, documented empirical evidence are also found in literature, for example, Nwosa and Oseni (2011) tested the weak-form efficiency of the Nigerian stock market using a sample data over the period 1986 to 2010 . The study specifically focused on the efficiency of the exchange after the sharp decline in stock prices following the global financial crisis. The tests were conducted using serial auto-correlation and regression method of analysis. The authors found that the market was informationally inefficient as the stock prices did not exhibit a random walk. The study recommended the need for strong and 
adequate supervision by the regulatory authorities and greater development of the market through appropriate policies that will increase the informational efficiency of the market. Ajao and Osayuwu (2012) tested the weak-form of EMH in the Nigerian capital market by analyzing the monthly closing value of the All Share Index from 2001 to 2010. The serial correlation technique of data analysis was used to test for independence of successive price movements, and the distributive pattern while the runs test was used to test for randomness of share price movement. The results of the study showed that successive price changes of stocks traded on the floor of the Nigerian capital market were independent and random, thus, the Nigerian capital market was weak-form efficient. In a similar development, Egbeonu (2016) empirically examined the validity of random walk hypothesis of security prices in Nigerian capital market. The study employed cross sectional security prices from selected quoted companies in Nigerian stock market using Q-statistic test, variance ratio, forecast error technique, Jarque-Bera normality test and EGARCH model. The results of the study supported the presence of random walk hypothesis in the behaviour of stock prices in Nigerian stock market.

Gbalam and Nelson (2019) assessed the weak form efficiency of the Nigerian stock exchange market using daily, weekly and monthly all share indices of the NSE. The study employed unit root tests of stationarity, random walk model, Jarque-Bera test of normality and graph presentation as analytical tools. The results revealed that the daily, weekly and monthly returns of the Nigerian stock exchange all exhibited significant random walk. The study concluded that the Nigerian stock exchange market was efficient in the weak form and recommended that efforts should be made by government to develop and implement stock exchange policies that will ensure active trading and vibrancy in the market. The empirical findings of Gbalam and Nelson (2019) are however criticized because the authors conducted their research on the stock prices instead of stock returns. The random movement of stock prices and efficiency of a stock market cannot be concluded on the basis of stock prices.

A careful survey of related empirical literature on the subject matter revealed that there is no consensus among researchers regarding the behaviour of stock market returns. The empirical results reported from both developed and developing countries including Nigeria produced mixed and conflicting results. Some researches provided evidence of weak form efficiency and could not reject the random walk hypothesis especially in emerging stock markets. This study contributes and extends the existing literature by empirically re-examining, re-assessing and reappraising the empirical evidence regarding the random walk and the efficiency market hypotheses in the Nigerian stock market using more robust statistical tests and more recent data.

\section{Materials and Methods \\ Data Source}

The data used in this study are the daily closing all share prices (ASI) of the Nigerian Stock Exchange (NSE) obtained from www.nse.org.ng and spanned from $2^{\text {nd }}$ January, 1998 to $31^{\text {st }}$ December, 2019. All the share prices are measured in Nigerian naira. The daily stock market prices are converted to daily log returns using the following formula:

$r_{t}=\ln \left[\frac{R_{t}}{R_{t-1}}\right] \times 100=\ln \left[R_{t}-R_{t-1}\right] \times 100$

where $r_{t}$ is the daily stock return series, $R_{t}$ is the daily closing value of the stock market index at the current day $t, R_{t-1}$ the daily closing value of the stock market index at the previous day $t-$ $1, \ln$ is the natural logarithm.

\section{Methods of Data Analysis}

The following statistical tools are employed in the analysis of data in this work.

\section{Descriptive Statistics and Normality Measures}

The mean of the daily stock return is computed as:

$\bar{r}=\frac{1}{n} \sum_{i=1}^{n} r_{i}$

The sample standard deviation of returns over a given period of time is computed using the following formula:

$$
\hat{\sigma}=\sqrt{\frac{1}{n-1} \sum_{t=1}^{n}\left(r_{t}-\bar{r}\right)}
$$


where $\bar{r}$ is the mean return, $n$ is the sample size. Jarque-Bera test is a normality test of whether a given sample data have the skewness and kurtosis similar to that of a normal distribution. The test was proposed by Jarque and Bera (1980, 1987) and test the null hypothesis that the series is normally distributed. Given a return series $\left\{r_{t}\right\}$ the test statistic JB is defined as:

$J B=\frac{T}{6}\left(g_{1}^{2}+\frac{1}{4}\left(g_{2}-3\right)^{2}\right)$

where $g_{1}$ is the sample skewness given as:

$g_{1}=\frac{\mu_{3}}{\mu_{2}^{3 / 2}}=\left[T^{\frac{1}{2}} \sum_{t=1}^{T}\left(r_{t}-\bar{r}\right)^{3}\right]\left[\sum_{t=1}^{T}\left(r_{t}-\bar{r}\right)^{2}\right]^{-3 / 2}$

and $g_{2}$ is the sample kurtosis defined by:

$g_{2}=\frac{\mu_{4}}{\mu_{2}^{2}}=\left[T \sum_{t=1}^{T}\left(r_{t}-\bar{r}\right)^{4}\right]\left[\sum_{t=1}^{T}\left(r_{t}-\bar{r}\right)^{2}\right]^{-2}$

where $\mu_{2}, \mu_{3}$, and $\mu_{4}$ are the second, third and fourth moments respectively, $\bar{r}$ is the return mean and $\mathrm{T}$ is the total number of observations. The JB normality test checks the following pair of hypothesis:

$H_{0}: \hat{\mu}_{3}=0$ and $\hat{\mu}_{4}=0$ (i.e., $r_{t}$ follows a normal distribution)

$H_{1}: \hat{\mu}_{3} \neq 0$ and $\hat{\mu}_{4} \neq 0$ (i.e., $r_{t}$ does not follows a normal distribution).

The test rejects the null hypothesis if the p-value of the JB test statistic is less than $\alpha=$ 0.05 level of significance.

\section{Augmented Dickey-Fuller (ADF) Unit Root Test}

A unit root is a statistical property of a series whose autoregressive parameter is one. Unit root tests are employ to examine whether the underlying time series data is stationary or contains a unit root. In this work, we employ the popular parametric Augmented Dickey-Fuller (ADF) unit root test due to Dickey and Fuller (1979). The ADF test constructs a parametric correction for higher-order correlation by assuming that the stock return series $\left(r_{t}\right)$ follows an $\operatorname{AR}(p)$ process and adding lagged difference terms of the dependent variable to the right-hand side of the test regression:

$$
\begin{aligned}
& \Delta r_{t}=\alpha r_{t-1}+x_{t}^{\prime} \delta+\phi_{1} \Delta r_{t-1}+\phi_{2} \Delta r_{t-2}+ \\
& \ldots+\phi_{p} \Delta r_{t-p}+\varepsilon_{t}
\end{aligned}
$$

where $x_{t}$ are optional exogenous regressors which may consist of constant, or a constant and trend, $\alpha$ and $\delta$ are parameters to be estimated, and the $\varepsilon_{t}$ are assumed to be white noise. The null and alternative hypotheses are written as:

$H_{0}: \alpha=0$ (i.e., the series contains a unit root)

$H_{1}: \alpha<0$ (i.e., the series is stationary)

and evaluated using the conventional $t$-statistic for $\alpha$ :

$t_{\alpha}=\hat{\alpha} / \operatorname{SE}(\hat{\alpha})$

where $\hat{\alpha}$ is the estimate of $\alpha$, and $\operatorname{SE}(\hat{\alpha})$ is the coefficient standard error. The test rejects the null hypothesis of a unit root if the ADF test statistic is smaller (i.e., more negative) than the asymptotic critical value at the designated test size or if the p-value of the ADF test statistic is less than $\alpha=0.05$.

\section{The Random Walk Model}

A random walk is a non-stationary process without a drift, with a drift or with a drift and deterministic time trend. Consider a simple random walk model without a drift below:

$r_{t}=\alpha r_{t-1}+\varepsilon_{t}$

where $\varepsilon_{t}$ is independently identically distributed with mean zero and variance $\sigma_{\varepsilon}^{2}$. The OLS of $\alpha$ is computed according to Dickey and Fuller (1979) as:

$\hat{\alpha}=\left(\sum_{t=2}^{T} r_{t-1}^{2}\right)^{-1}\left(\sum_{t=2}^{T} r_{t} r_{t-1}\right)$

The model checks the following pairs of hypothesis

$H_{0}: \alpha=0$ (i.e., $r_{t}$ is random walk)

$H_{0}: \alpha<0$ (i.e., $r_{t}$ is stationary process)

Consider a random walk model with a drift which is an extension of equation (3.9)

$r_{t}=\mu+\alpha r_{t-1}+\varepsilon_{t}$

If $\mu \neq 0,\left(r_{t}\right)$ has a linear deterministic trend and $\mu$ is called a drift. The OLS of $\alpha$ in (3.11) is given by

$\hat{\alpha}=\left(\sum\left(r_{t-1}-\bar{r}_{-1}\right)^{2}\right)^{-1}\left(\sum\left(r_{t-1}-\bar{r}_{-1}\right)\left(r_{t-1}-\bar{r}\right)\right)$

where $\bar{r}_{-1}=\frac{1}{T-1} \sum_{t=1}^{T} r_{t}$ and $\bar{r}=\frac{1}{T-1} \sum_{t=2}^{T} r_{t}$

The model tests the following pairs of hypothesis

$H_{0}: \alpha=0, \mu \neq 0$ (i.e., $r_{t}$ is random walk around a drift)

$H_{0}: \alpha<0, \mu \neq 0$ (i.e., $r_{t}$ is a level stationary process) 
Consider a random walk model with a drift and linear trend below

$r_{t}=\mu+\beta t+\alpha r_{t-1}+\varepsilon_{t}$

If $\mu=0$ and $\alpha=1,\left(r_{t}\right)$ contains at most a constant trend and

$$
\begin{gathered}
T(\hat{\alpha}-1) \stackrel{D}{\rightarrow}\left(\int_{0}^{1} w_{1}(r)^{2} d r\right)^{-1}\left(\int_{0}^{1} w_{1}(r) d w(r)\right) \\
\text { where } w_{1}(r)=w(r)-\int_{0}^{1} w(s) d s
\end{gathered}
$$

The F-statistic to test

$$
\begin{aligned}
& (\mu, \alpha)=(0,1) \stackrel{D}{\rightarrow} \frac{1}{2} \\
& {\left[\left(\int_{0}^{1} d w(r)^{2}\right)+\left(\int_{0}^{1} w_{1}(r)^{2} d r\right)^{-1}\left(\int_{0}^{1} w_{1}(r) d w(r)\right)^{2}\right]}
\end{aligned}
$$

But if $\beta \neq 0$ and $\alpha=1,\left(r_{t}\right)$ contains a quadratic trend and the situation is analogous to the case where $\mu \neq 0$ and $\alpha=1$. However, Dickey-Fuller test does not admit $\beta \neq 0$ and $\alpha=$ 1. If $(\beta, \alpha)=(0,1)$, then

$T(\hat{\alpha}-1) \stackrel{D}{\rightarrow}\left(\int_{0}^{1} w_{2}(r)^{2} d r\right)^{-1}\left(\int_{0}^{1} w_{2}(r) d w(r)\right)$

The F-statistic to test

$$
\begin{aligned}
& (\mu, \alpha)=(0,1) \stackrel{D}{\rightarrow} \frac{1}{2} \\
& {\left[12\left(\int_{0}^{1}\left(r-\frac{1}{2}\right) d w(r)^{2}\right)+\left(\int_{0}^{1} w_{2}(r)^{2} d r\right)^{-1}\left(\int_{0}^{1} w_{2}(r) d w(r)\right)^{2}\right](3.16)}
\end{aligned}
$$

The random walk model with drift and linear time trend tests the following pairs of hypothesis

$H_{0}: \alpha=0, \beta \neq 0$ (i.e., $r_{t}$ is random walk around a trend)

$H_{0}: \alpha<0, \beta \neq 0$ (i.e., $r_{t}$ is a trend stationary process)

These statistics can be used in testing difference stationary against trend stationarity in the presence of a deterministic trend. In testing the random walk hypothesis, if the calculated value of the ADF test statistic exceeds the test asymptotic critical values, the hypothesis that $\alpha=0$ is rejected indicating that the series is stationary. If, however, the calculated ADF test statistic does not exceed the critical value, the null hypothesis is not rejected and the series is said to be nonstationary.

\section{Autocovariance and Autocorrelation Functions}

For a stationary time series process $\left\{r_{t}\right\}$, the covariance between $r_{t}$ and $r_{t+k}$ is given by Durbin (1960) as

$\gamma_{k}=\operatorname{Cov}\left(r_{t}, r_{t+k}\right)=E\left(r_{t}-\mu\right)\left(r_{t+k}-\mu\right)$

and the correlation between $r_{t}$ and $r_{t+k}$ is given as

$\rho_{k}=\frac{\operatorname{Cov}\left(r_{t}, r_{t+k}\right)}{\sqrt{\operatorname{var}\left(r_{t}\right)} \sqrt{\operatorname{var}\left(r_{t+k}\right)}}=\frac{\gamma_{k}}{\gamma_{0}}$

where $\gamma_{k}$ is the autocovariance function and $\rho_{k}$ is the autocorrelation function (ACF) representing the covariance and correlation between $r_{t}$ and $r_{t+k}$ from the same process separated only by $k$ time lags. For a given observed time series $r_{1}, r_{2}, \ldots, r_{n}$, the sample autocorrelation function (ACF) is computed as

$\hat{\rho}_{k}=\frac{\hat{\gamma}_{k}}{\hat{\gamma}_{0}}=\sum_{t=1}^{n-k}\left(r_{t}-\bar{r}\right)\left(r_{t+k}-\bar{r}\right) / \sum_{t=1}^{n}\left(r_{t}-\bar{r}\right)^{2}, \quad k=0,1,2$,

(3.19)

where $\bar{r}$ is defined in (3.2).

The partial autocorrelation between $r_{t}$ and $r_{t+k}$ is equal to the ordinary autocorrelation between $\left(r_{t}-\hat{r}_{t}\right)$ and $\left(r_{t+k}-\hat{r}_{t+k}\right)$. Let $\phi_{k k}$ denotes the partial autocorrelation between $r_{t}$ and $r_{t+k}$, then we have

$$
\phi_{k k}=\frac{\operatorname{Cov}\left[\left(r_{t}-\hat{r}_{t}\right)\left(r_{t+k}-\hat{r}_{t+k}\right)\right]}{\sqrt{\operatorname{var}\left(r_{t}-\hat{r}_{t}\right)} \sqrt{\operatorname{var}\left(r_{t+k}-\hat{r}_{t+k}\right)}}
$$

A recursive procedure for computing the sample partial autocorrelation function (PACF) starting with $\phi_{11}=\hat{\rho}_{1}$ for computing $\phi_{k k}$ was given by Durbin (1960) as

$\hat{\phi}_{k+1, k+1}=\hat{\rho}_{k+1}-\sum_{j=1}^{k} \hat{\phi}_{k j} \hat{\rho}_{k+1-j} /\left(1-\sum_{j=1}^{k} \hat{\phi}_{k j} \hat{\rho}_{j}\right)$

and $\hat{\phi}_{k+1, j}=\hat{\phi}_{k j}-\hat{\phi}_{k+1, k+1} \hat{\phi}_{k, k+1-j}, j=$ $1,2, \ldots, k$. This procedure also holds for computing the theoretical PACF $\phi_{k k}$.

\section{Ljung-Box Q-Statistic Test}

The Ljung-Box test is a test for investigating the presence of serial correlation/autocorrelation as well as randomness in time series data. The test checks the following pairs of hypotheses:

$H_{0}: \rho_{k, 1}=\rho_{k, 2}=\cdots=\rho_{k, T}=0 \quad$ (all lags correlations are zero)

$H_{1}: \rho_{k, 1} \neq \rho_{k, 2} \neq \cdots \neq \rho_{k, T} \neq 0$ (there is at least one lag with non-zero correlation).

The Ljung-Box Q-statistic test is given by: 
$Q^{(L B)}=T(T+2) \sum_{k=1}^{h} \frac{\hat{\rho}_{k}^{2}}{T-k}$

where

$\hat{\rho}_{k}^{2}=\frac{T}{T-k}\left(T \sum_{t=k+1}^{T}\left(\hat{\varepsilon}_{t}^{2}-\bar{\varepsilon}\right)\left(\hat{\varepsilon}_{t-k}^{2}-\bar{\varepsilon}\right) / \sum_{t=1}^{T}\left(\hat{\varepsilon}_{t}^{2}-\bar{\varepsilon}\right)^{2}\right)$, for $\bar{\varepsilon}=T^{-1} \sum_{t=1}^{T} \varepsilon_{t}^{2}$

denotes the autocorrelation estimate of squared standardized residuals at $k$ lags. $\mathrm{T}$ is the sample size, $\mathrm{Q}$ is the sample autocorrelation at lag $\mathrm{k}$. Theoretically, the Q-statistic is asymptotically chi-square distributed with degree of freedom equal to the number of autocorrelations. We reject $H_{0}$ if $\mathrm{p}$-value of the test is less than $\alpha=0.05$ level of significance (Ljung and Box, 1978).

\section{The Runs Test}

Runs test is a non-parametric test use to examine the randomness or serial dependence of returns in a stock market. The runs test is also use to investigate the random walk behaviour since the test ignores the properties of distribution and independent of the constant variance of data and normality. A run is computed as a sequence of price changes of the same sign (positive sign) preceded and followed by the price changes of different sign (negative sign). Under the null hypothesis that sequences are serially independent and random, and if the expected number of runs is different from the actual number of runs then we will reject the null hypothesis of randomness.

To perform the runs test, the number of actual runs denoted by $(R)$ is computed and compared with the expected number of runs $(\mathrm{m})$ which according to Fama (1970) can be estimated as:

$$
m=\frac{1}{N}\left[N(N+1)-\sum_{i=1}^{3} n_{i}^{2}\right]
$$

When $n>30$, the sampling distribution of $m$ is approximately normal with standard deviation $\left(\sigma_{m}\right)$ for runs given as:

$\sigma_{m}=\left[\frac{1}{N^{2}(N-1)}\left[\sum_{i=1}^{3}\left(\sum_{i=1}^{3} n_{i}^{2}+N(N+1)\right)-2 N\left(\sum_{i=1}^{3} n_{i}^{3}-N^{3}\right)\right]\right]^{\frac{1}{2}}(3.24)$

where $m=$ the expected number of runs, $N=$ total number of return observations, $n_{i}=$ total number of price changes (returns) in the $i$ th category.

The standard normal Z-statistic is then used to compute the runs test as:

$Z=\frac{R \pm 0.5-m}{\sigma_{m}}$ where $R=$ actual number of runs, $0.5=$ continuity adjustment. The continuity adjustment is positive if $R \leq m$ and negative if $R \geq m$. The runs test tests the following pair of hypothesis:

$H_{0}$ : The return series is random vs $H_{1}$ : The return series is not random.

If $R<m, Z$-value will be negative, indicating the presence of positive serial correlation and if $R>m, Z$-value will be positive indicating the presence of negative serial correlations. When there is presence of positive serial correlation in stock returns, it indicates the positive dependence of stock returns and this implies the violation of random walk hypothesis. That is, the null hypothesis of randomness of the return series is rejected. If the $p$-value obtained from the runs test is less than $\alpha=0.05$, then test will be significant but if the p-value is greater than 0.05 , then the test will not be significant.

\section{The Variance Ratio (VR) Test}

Lo and Mackinlay (1988) developed the variance ratio test for testing the randomness in stock market prices and were able to show that the VR test was more powerful than the unit root test in examining the random walk behaviour in stock prices.

The VR procedure tests whether the ratio of the variance of $q$-period returns by $q$ times the variance of 1-period returns is statistically not different from one. The Variance ratio test under homoscedasticity assumption, using overlapping observations is defined as

$\operatorname{Var}(q)$

$=\frac{\sigma_{c}^{2}(q)}{\sigma_{a}^{2}(q)}$

where $\sigma_{c}^{2}(q)$ is an unbiased estimator of $1 / q$ of the variance of the $q^{\text {th }}$-difference and $\sigma_{a}^{2}(q)$ is an unbiased estimator of the variance of the $1^{\text {st }}$-difference. The standard normal teststatistics under homoscedasticity assumption $Z(q)$ is given by

$Z(q)=\frac{V R(q)-1}{\sqrt{\Phi(q)}} \sim N(0,1)$

where

$\Phi(q)=\frac{2(2 q-1)(q-1)}{3 q(n q)} \sim N(0,1)$

Under the heteroscedasticity assumption, the VR test is given by

$Z^{*}(q)=\frac{V R(q)-1}{\sqrt{\Phi^{*}(q)}} \sim N(0,1)$ 
where

$\Phi^{*}(q)=\sum_{j=1}^{q-1}\left[\frac{2(q-j)}{q}\right]^{2} \hat{\sigma}(j)$

where

$\hat{\sigma}(j)=$

$\sum_{t=j+1}^{n q}\left(P_{t}+P_{t-1}-\hat{\mu}\right)^{2}\left(P_{t-j}-P_{t-j-1}-\hat{\mu}\right)^{2} /\left[\sum_{k=1}^{n q}\left(P_{t}+P_{t-1}-\hat{\mu}\right)^{2}\right]^{2}(3.31)$

where $\hat{\sigma}(j)=$ heteroscedasticity consistent estimator; $\hat{\mu}=$ average return; $P_{t}=$ average price of security at time $t$.

Based on the test statistics $Z(q)$ and $Z^{*}(q)$, if the variance ratio test is greater than unity $(V R>1)$, it means there is positive serial correlation in the return series and we conclude that the return series are predictable hence the homoskedastic and heteroskedastic random walk can be rejected. If the variance ratio test is less than unity $(V R<1)$, it implies that there is negative serial correlation in the return series and conditional variances respectively.

\section{Results and Discussion \\ Summary Statistics and Normality Measures of Stock Returns}

The summary statistics and normality measures which aid in understanding the distributional characteristics of the stock returns are presented in Table 1.

Table 1: Summary Statistics and Normality Measures of Daily Stock Returns

\begin{tabular}{ll}
\hline Statistic & Value \\
\hline Mean & 0.028103 \\
Median & -0.000231 \\
Maximum & 11.26503 \\
Minimum & -12.54935 \\
Standard Deviation & 0.999570 \\
Skewness & -0.054322 \\
Kurtosis & 14.08008 \\
Jarque-Bera & 27758.48 \\
P-value & 0.000000 \\
Number of Observations & 5426 \\
\hline
\end{tabular}

From the results of summary statistics and normality measures reported in Table 1 , observe that the daily mean return is positive $(0.028103)$ indicating gain in the stock market during the trading period under consideration. The high values of the daily range return and the standard deviation show a high level of variability of price changes in the Nigerian stock market.

The skewness of the stock market return series is negative indicating that the stock index returns are flatter and skewed to the left as compared to the normal distribution. This implies that the asymmetric tail of the return series extends more towards negative values than positive ones. The kurtosis value of the returns is very high indicating that the stock return distribution has sharp peak when compared to a normal distribution. This suggests that the return distribution is heavy tailed. Additionally, the high value of Jarque-Bera statistic with marginal probability value of 0.0000 confirms the deviation of the daily stock returns from normality.

\section{ADF Unit Root Test Result for Daily Stock Returns}

Unit root test is a statistical test for investigating stationarity in time series. To investigate the random walk hypothesis (RWH), unit root test of stationarity (absence of randomness) is very necessary. In this work Augmented Dickey-Fuller (ADF) unit root test has been employed for this purpose. The results of the ADF unit root test is presented in Table 2.

Table 2: ADF Unit Root Test Result for NSE Returns

\begin{tabular}{llll}
\hline Year & ADF Test Statistic & P-value & 5\% Critical value \\
\hline $\mathbf{1 9 9 8}$ & -14.6185 & 0.0000 & -3.4280 \\
$\mathbf{1 9 9 9}$ & -10.1360 & 0.0000 & -3.4280 \\
$\mathbf{2 0 0 0}$ & -8.8359 & 0.0000 & -3.4280 \\
$\mathbf{2 0 0 1}$ & -8.9302 & 0.0000 & -3.4281 \\
$\mathbf{2 0 0 2}$ & -9.9151 & 0.0000 & -3.4281 \\
$\mathbf{2 0 0 3}$ & -8.1800 & 0.0000 & -3.4280 \\
$\mathbf{2 0 0 4}$ & -8.7036 & 0.0000 & -3.4281 \\
\hline
\end{tabular}




\begin{tabular}{llll}
\hline $\mathbf{2 0 0 5}$ & -9.2118 & 0.0000 & -3.4276 \\
$\mathbf{2 0 0 6}$ & -9.1073 & 0.0000 & -3.4282 \\
$\mathbf{2 0 0 7}$ & -9.6082 & 0.0000 & -3.4286 \\
$\mathbf{2 0 0 8}$ & -7.7236 & 0.0000 & -3.4381 \\
$\mathbf{2 0 0 9}$ & -8.3019 & 0.0000 & -3.4282 \\
$\mathbf{2 0 1 0}$ & -12.1005 & 0.0000 & -3.4280 \\
$\mathbf{2 0 1 1}$ & -11.7562 & 0.0000 & -3.4286 \\
$\mathbf{2 0 1 2}$ & -14.0069 & 0.0000 & -3.4283 \\
$\mathbf{2 0 1 3}$ & -13.2558 & 0.0000 & -3.4282 \\
$\mathbf{2 0 1 4}$ & -9.2352 & 0.0000 & -3.4289 \\
$\mathbf{2 0 1 5}$ & -9.6604 & 0.0000 & -3.4282 \\
$\mathbf{2 0 1 6}$ & -9.0840 & 0.0000 & -3.4285 \\
$\mathbf{2 0 1 7}$ & -11.3215 & 0.0000 & -3.4285 \\
$\mathbf{2 0 1 8}$ & -13.7947 & 0.0000 & -3.4281 \\
$\mathbf{2 0 1 9}$ & -12.1947 & 0.0000 & -3.4282 \\
Full Sample & -49.0189 & 0.0000 & -3.4106 \\
\hline
\end{tabular}

Table 2 reported ADF unit root test for both yearly from 1998 to 2019 and full sample period. The ADF test statistics showed that the stock returns of the Nigeria stock market from 1998 to 2019 are stationary at the $1 \%$ marginal significance level. Therefore, the null hypothesis that the Nigerian stock market prices contain unit root is rejected. This is shown by the ADF test statistics being smaller than the corresponding asymptotic 5\% critical values and the significant p-values of the ADF test statistics.

The random walk hypothesis (RWH) is supported if the stock market returns series contain unit root and are non-stationary. Since the unit root null hypothesis is rejected by the ADF unit root test across the study periods, it means that the stock market return series of the NSE are covariance-stationary and hence weak-form inefficient and investors can predict the stock market returns.

\section{Autocorrelations and Ljung-Box $Q$-statistics Test Results of Returns}

The current study also employs LjungBox Q-statistic test to investigate the presence of serial correlation and randomness of NSE stock return series. The result of autocorrelation function (ACF), partial autocorrelation function (PACF) and Ljung-Box Q-statistic tests for the residuals and squared residuals up to lag 36 are presented in Table 3.

Table 3: Autocorrelations and Ljung-Box Q-statistics for NSE Daily Returns

\begin{tabular}{ccccccccc}
\hline \multirow{2}{*}{ Lag } & \multicolumn{4}{c}{ Residuals } & \multicolumn{5}{c}{ Squared Residuals } \\
\cline { 2 - 9 } $\mathbf{1}$ & ACF & PACF & Q-Stat. & P-value & ACF & PACF & Q-Stat. & P-value \\
$\mathbf{2}$ & 0.386 & 0.386 & 810.04 & 0.000 & 0.462 & 0.462 & 1160.2 & 0.000 \\
$\mathbf{3}$ & 0.173 & 0.028 & 972.34 & 0.000 & 0.065 & -0.189 & 1183.3 & 0.000 \\
$\mathbf{4}$ & 0.036 & -0.047 & 979.28 & 0.000 & 0.036 & 0.116 & 1190.4 & 0.000 \\
$\mathbf{5}$ & 0.004 & 0.001 & 979.37 & 0.000 & 0.022 & -0.048 & 1193.0 & 0.000 \\
$\mathbf{6}$ & 0.005 & 0.012 & 979.53 & 0.000 & 0.022 & 0.042 & 1195.6 & 0.000 \\
$\mathbf{7}$ & -0.025 & -0.035 & 983.04 & 0.000 & 0.028 & 0.001 & 1199.8 & 0.000 \\
$\mathbf{8}$ & -0.018 & 0.001 & 984.89 & 0.000 & 0.018 & 0.005 & 1201.5 & 0.000 \\
$\mathbf{9}$ & -0.010 & 0.004 & 985.45 & 0.000 & 0.012 & 0.004 & 1202.3 & 0.000 \\
$\mathbf{1 0}$ & 0.018 & 0.025 & 987.21 & 0.000 & 0.033 & 0.034 & 1208.3 & 0.000 \\
$\mathbf{1 5}$ & 0.022 & 0.007 & 989.75 & 0.000 & 0.026 & -0.009 & 1212.1 & 0.000 \\
$\mathbf{2 0}$ & 0.018 & 0.006 & 1006.2 & 0.000 & 0.009 & -0.005 & 1217.4 & 0.000 \\
$\mathbf{2 5}$ & 0.012 & -0.004 & 1013.7 & 0.000 & 0.008 & 0.013 & 1223.1 & 0.000 \\
$\mathbf{3 0}$ & 0.028 & 0.003 & 1038.9 & 0.000 & 0.002 & -0.000 & 1223.9 & 0.000 \\
$\mathbf{3 5}$ & -0.015 & -0.010 & 1076.9 & 0.000 & 0.005 & 0.008 & 1224.9 & 0.000 \\
$\mathbf{3 6}$ & -0.017 & -0.011 & 1084.0 & 0.000 & -0.000 & -0.004 & 1226.0 & 0.000 \\
\hline
\end{tabular}

The Ljung-Box Q-statistic test for serial correlation and randomness of stock returns reported in Table 3 is based on the null hypothesis that there is no serial correlation/autocorrelation in the residuals and squared residuals of NSE stock return series. Both the results of Ljung-Box Q-statistics test and the non-zero autocorrelations of stock returns series are jointly statistically significant at the $1 \%$ marginal significance levels. This means that the null hypothesis of no serial 
correlation in the residuals and squared residuals of NSE stock returns is rejected indicating the presence of serial correlation/autocorrelation in the residual series. The implication is that the NSE stock returns are not random but inefficient at the weak-form level. The inefficiency of the NSE stock market means that the stock prices do not incorporate instantly all historical information and hence technical analysis as a trading strategy may be of much value in the market.

\section{The Runs Test Result for Randomness of Returns}

Runs test is a non-parametric test used to examine the randomness or serial dependence of stock return series. The runs test is a more robust statistical test than the Ljung-Box Q-statistic test for serial correlation. The runs tests are performed for both median, mean and mode values of returns and the results are reported in Table 4.

Table 4: The Runs Test Result for Randomness of Returns

\begin{tabular}{llll}
\hline & Median & Mean & Mode \\
\hline Test value & -0.000231 & 0.028103 & 0.00000 \\
Cases $(\boldsymbol{m})<$ Test value & 2713 & 2922 & 2755 \\
Cases $(\boldsymbol{m}) \geq$ Test value & 2713 & 2504 & 2671 \\
Total Cases $(\boldsymbol{m})$ & 5426 & 5426 & 5426 \\
Number of Runs $(\boldsymbol{R})$ & 2102 & 2054 & 2094 \\
Z-Statistic & -16.618 & -17.589 & -16.822 \\
P-value & 0.0000 & 0.0000 & 0.0000 \\
\hline
\end{tabular}

From the results of runs tests reported in Table 4, observe that the Z-statistic values for the median, mean and mode tests are all negative indicating that the actual runs are less than the expected runs. This means there is a positive serial correlation in the stock return series (i.e., the stock return series do not move randomly). More so, the p-values of the Z-statistics are (0.0000), less than $\alpha=0.05$. This means that the runs test is statistically significant at the $1 \%$ level of significance and the null hypothesis that the NSE stock return series follows a random walk (RW) is rejected. The implication of this result is that the NSE stock returns series are not random but are predictable with non-random walk behaviour.

Based on the result of the runs test, it can be concluded that the daily stock return series does not move randomly hence the NSE is a weak form inefficient market. An inefficient stock market means that stock market prices are predictable, dependable, consistently mispriced, liable to arbitraging and left unprotected to market speculations and manipulations. An inefficient stock market can seriously suffer from inflated stock prices, insider trading and speculation which could have negative effects on investor's confidence.

\section{Variance Ratio Test Results}

We expand our investigation on statistical tests regarding the empirical evidence on the random walk hypothesis and the weak-form efficiency in NSE by employing a more robust statistical test, the variance ratio test due to (Lo and Mackilay, 1988). The results of the tests for both homoskedasticity and heteroskedasticity assumptions for the full sample period and individual (yearly) periods are reported in Tables 5,6 and 7

Table 5: Variance Ratio Test Result-Homoskedasticity Assumption (Full Sample)

\begin{tabular}{|c|c|c|c|c|}
\hline \multicolumn{5}{|c|}{ Null Hypothesis: NSE_ASI_RETURNS is a Random Walk } \\
\hline Joint Tests & Value & Df & Probability & \\
\hline $\operatorname{Max}|z|($ at period 2) & 16.03430 & 5425 & 0.0000 & \\
\hline Wald (Chi-Square) & 295.1912 & 15 & 0.0000 & \\
\hline \multicolumn{5}{|c|}{ Individual Tests } \\
\hline Period & Var. Ratio & Std. Error & z-Statistic & Probability \\
\hline 2 & 0.473876 & 0.043093 & -12.20915 & 0.0000 \\
\hline 3 & 0.461346 & 0.045841 & -11.75053 & 0.0000 \\
\hline 4 & 0.450959 & 0.048436 & -11.33540 & 0.0000 \\
\hline 5 & 0.441045 & 0.050901 & -10.98128 & 0.0000 \\
\hline 6 & 0.432598 & 0.053253 & -10.65484 & 0.0000 \\
\hline 7 & 0.428124 & 0.055507 & -10.30286 & 0.0000 \\
\hline 8 & 0.421198 & 0.057673 & -10.03594 & 0.0000 \\
\hline 16 & 0.415622 & 0.059761 & -9.778512 & 0.0000 \\
\hline
\end{tabular}


Table 6: Variance Ratio Test Result-Heteroskedasticity Assumption (Full Sample)

\begin{tabular}{lcccc}
\hline \multicolumn{4}{l}{ Null Hypothesis: NSE_ASI_RETURNS is a Martingale } & \\
\hline Joint Test & Value & Df & Probability & \\
Max $|\mathbf{z}|$ (at period 2) & 18.84237 & 5425 & 0.0000 & \\
& & & \\
Period & Var. Ratio & Individual Tests & z-Statistic & Probability \\
$\mathbf{2}$ & 0.782304 & Std. Error & -16.03430 & 0.0000 \\
$\mathbf{3}$ & 0.686144 & 0.013577 & -15.50729 & 0.0000 \\
$\mathbf{4}$ & 0.627281 & 0.020239 & -14.67396 & 0.0000 \\
$\mathbf{5}$ & 0.577659 & 0.025400 & -14.19850 & 0.0000 \\
$\mathbf{6}$ & 0.547957 & 0.029745 & -13.46851 & 0.0000 \\
$\mathbf{7}$ & 0.516208 & 0.033563 & -13.07392 & 0.0000 \\
$\mathbf{1 6}$ & 0.495853 & 0.037004 & -12.55317 & 0.0000 \\
\hline
\end{tabular}

Table 7: Sign Variance Ratio Test on Returns-Joint Tests (Individual Years)

\begin{tabular}{lllll}
\hline Period & Max $|\mathbf{z}|$ at $\mathbf{2}$ Periods & \multicolumn{3}{c}{ Wald (Chi-Square) } \\
\cline { 2 - 4 } $\mathbf{1 9 9 8}$ & Test Value & Probability & Test Value & Probability \\
$\mathbf{1 9 9 9}$ & 16.0343 & 0.0000 & 65.5912 & 0.0000 \\
$\mathbf{2 0 0 0}$ & 4.0640 & 0.0000 & 27.2702 & 0.0430 \\
$\mathbf{2 0 0 1}$ & 3.6268 & 0.0000 & 33.7166 & 0.0090 \\
$\mathbf{2 0 0 2}$ & 5.0267 & 0.0000 & 53.7328 & 0.0000 \\
$\mathbf{2 0 0 3}$ & 3.8100 & 0.0000 & 32.2508 & 0.0130 \\
$\mathbf{2 0 0 4}$ & 3.4996 & 0.0000 & 29.1822 & 0.0310 \\
$\mathbf{2 0 0 5}$ & 3.1366 & 0.0060 & 28.2588 & 0.0341 \\
$\mathbf{2 0 0 6}$ & 2.8511 & 0.0140 & 28.6964 & 0.0220 \\
$\mathbf{2 0 0 7}$ & 3.6566 & 0.0001 & 31.8354 & 0.0128 \\
$\mathbf{2 0 0 8}$ & 3.8170 & 0.0000 & 27.9552 & 0.0413 \\
$\mathbf{2 0 0 9}$ & 3.8452 & 0.0000 & 28.9636 & 0.0330 \\
$\mathbf{2 0 1 0}$ & 3.2802 & 0.0065 & 29.7550 & 0.0230 \\
$\mathbf{2 0 1 1}$ & 2.4791 & 0.0310 & 27.1452 & 0.0431 \\
$\mathbf{2 0 1 2}$ & 2.8168 & 0.0350 & 27.3893 & 0.0219 \\
$\mathbf{2 0 1 3}$ & 4.0805 & 0.0000 & 32.1584 & 0.0130 \\
$\mathbf{2 0 1 4}$ & 4.8994 & 0.0000 & 37.4737 & 0.0030 \\
$\mathbf{2 0 1 5}$ & 3.8718 & 0.0000 & 27.3050 & 0.0405 \\
$\mathbf{2 0 1 6}$ & 4.0742 & 0.0020 & 28.1911 & 0.0460 \\
$\mathbf{2 0 1 7}$ & 3.7299 & 0.0000 & 27.2909 & 0.0430 \\
$\mathbf{2 0 1 8}$ & 3.1910 & 0.0060 & 28.0124 & 0.0260 \\
$\mathbf{2 0 1 9}$ & 6.4265 & 0.0000 & 63.0283 & 0.0000 \\
Full Sample & 3.8493 & 0.0020 & 36.6789 & 0.0060 \\
\hline
\end{tabular}

The results of the variance ratio test under homoskedasticity assumption as reported in Table 5 strongly reject the null hypothesis of a random walk for both joint tests and test of individual periods. The null hypothesis of the variance ratio tests (NSE ASI RETURNS is a random walk) are strongly rejected with marginal p-values of 0.0000. This means that the NSE stock returns do not follow a random walk. From the results of variance ratio test under heteroskedasticity assumption reported in Table 6, the p-values for both joint test and test for individual periods are highly statistically significant at $1 \%$ marginal significance levels, indicating the rejection of the null hypothesis (NSE ASI RETURNS is a martingale). The VR tests under heteroskedasticity assumption are also strongly rejected with marginal p-values of 0.0000 . This means that the NSE stock returns do not follow a random walk. Similarly, the null hypotheses of random walks and martingales for the joint tests of the VR for the individual years from 1998 to 2019 including the full sample period are all rejected at $1 \%$ marginal probability values.

Based on the results of variance ratio tests, it is concluded that the Nigerian daily stock return series do not move in a random fashion and hence the null hypothesis of a random walk is rejected, thus the Nigerian Stock Market is a weak-form inefficiency market.

\section{Conclusion and Recommendations}

This study empirically examined the random walk hypothesis in the Nigerian stock market using the daily quotations of the Nigerian stock exchange from $2^{\text {nd }}$ January, 1998 to $31^{\text {st }}$ December, 2019. The study employs DickeyFuller Generalized Least Squares unit root test, the random walk model, Ljung-Box Q-statistic test for serial dependence, runs test of randomness, and the robust variance ratio test as methods of 
analyses. The result of the ADF unit root test rejected the null hypotheses of a unit root and random walk in the stock market returns. The null hypothesis of no serial correlation in the residuals of stock returns was also rejected indicating the presence of serial correlation/autocorrelation in the residual series.

The result of the runs test rejected the null hypothesis of randomness in the Nigerian stock returns. The results of the variance ratio test under homoskedasticity and heteroskedasticity assumptions both strongly rejected the null hypothesis of a random walk for both joint tests and test of individual periods. Based on the results of the four tests applied in this study, it is concluded that the Nigerian daily stock returns under the period of investigation do not follow a random walk and hence the null hypothesis of a random walk is rejected. The results of the four statistical tests employed in this study namely, ADF unit root test for stationarity, Ljung-Box Qstatistic serial correlation test, the runs test and the variance ratio tests are consistent.

All the four results have revealed that the daily stock return series of the Nigerian Stock Market do not move randomly. Based on the findings of this study, it is concluded that the null hypothesis of a random walk in NSE is rejected and the Nigerian stock market is described as a weak form inefficient market indicating that prices in the Nigerian stock market are predictable, dependable, consistently mispriced, inflated, liable to arbitraging and left unprotected to speculations and market manipulations.

Based on the empirical findings of this study, the following recommendations are hereby presented.

i. Stock market regulators should ensure prompt disclosure and dissemination of available information on the performance of securities to traders and investors.

ii. Efforts should be made by government and the Nigerian stock market operators to address trading frictions, develop and implement stock exchange policies that will ensure active trading and vibrancy in the market.

\section{References}

Abbas, G. (2014). Testing Random Walk Behavior in the Damascus Securities Exchange. International Journal of Academic Research in Accounting,
Finance and Management Sciences, 4(4): 317-325.

Abina, A. P. (2019). Capital Market and Performance of Nigeria Economy. International Journal of Innovative Finance and Economics Research, 7(2): 51-66.

Abushammala, S. (2011). Testing the Weak Form Efficiency of Palestine Exchange. International Journal of Economics and Finance, 3(6): 244-252.

Adelegan, O. J. (2003). Capital Market Efficiency and the Effects of Dividend Announcements on Share Prices in Nigeria. African Development Review, 15(3): 218-236.

Adigwe, P. K., Ugbomhe, O. U., and Alajekwu, U. B. (2017). Test of Weak Form Stock Market Efficiency in Selected African Stock Markets (2013 - 2015). Saudi Journal of Business and Management Studies, 2(2): 60-69.

Afrafayia, A. A. (2018). Effect of Liberalization of Amman Stock Market on the Prices Fluctuation. Asian Journal of Finance \& Accounting, 10(1): 274-294.

Ajao, M. G., and Osayuwu, R. (2012). Testing the Weak-Form of Efficient Market Hypothesis in Nigerian Capital Market. Accounting and Finance Research, 1(1): 169-179.

Aliyev, F. (2019). Testing Market Efficiency with Nonlinear Methods: Evidence from Borsa Istanbul. International Journal of Financial Studies, 7(27): 1-11.

Dickey, D. A., and Fuller, W. A. (1979). Distribution of the Estimates of Autoregressive Time Series with a Unit Root. Journal of the American Statistical Association, 74: 427-431.

Durbin, J. (1960). The Fitting of Time Series Models. Review of the Institute of International Statistics, 28: 233-244.

Egbeonu, O. C. (2016). Random Walk Hypothesis of Security Prices in Nigeria Stock Market. International Journal of Advanced Academic Research, Social \& Management Sciences, 2(5): 32-40.

Fama, E. F. (1970). Efficient Capital Markets: A Review of Theory and Empirical Work. Journal of Finance, 25(2): 383-417. 
Gbalam, P. E., and Nelson, J. (2019). Testing the Weak Form Efficiency of the Nigeria Stock Exchange Market. European Journal of Accounting, Auditing and Finance Research, 7(10): 10-22.

Izz Eddien, N. A. (2016). Weak Form Efficiency of the Amman Stock Exchange: An Empirical Analysis (2000-2013). International Journal of Business and Management, 11(1): 173-180.

Izz Eddien, N. A. (2014). Testing the Weak Form of Efficient Market Hypothesis: Empirical Evidence from Jordan. International Business and Management, 9(2): 119-123.

Jarque, C. M., Bera, A. K. (1980). Efficient Test for Normality, Heteroskedasticity and Serial Independence of Regression Residuals. Econometric Letters, 6: 255259.

Jarque, C. M., Bera, A. K. (1987). A Test for Normality of Observations and Regression Residuals. International Statistical Review, 55(2): 163-172.

Kumar, S., and Kumar, L. (2015). Market Efficiency in India: An Empirical Study of Random Walk Hypothesis of Indian Stock Market-NSE Midcap. Zenith International Journal of Multidisciplinary Research, 5(1):167-177.

Ljung, G. M., and Box, G. E. P. (1978). On a Measure of Lack of Fit in Time Series Models. Biometrica, 65: 297-303.

Lo, A.W., and Mackinlay, A. C. (1988). Stock Market Prices do not Follow Random Walks: Evidence from a Simple Specification Test. The Review of Financial Studies, 1(1): 41-66.

Maximillian, M. K., and Gwahula, R. (2018). An Empirical Analysis of Weak-Form
Efficiency of Dar es Salaam Stock Exchange. African Journal of Economic Review, 6(2): 115-134.

McKerrow, A. (2013). Random Walks in Frontier Stock Markets. Ghanaian Journal of Economics, 1: 87-103.

Nisar, S and Hanif, M. (2012). Testing Weak Form of Efficient Market Hypothesis: Empirical Evidence from South-Asia. World Applied Sciences Journal, 17(4): 414-427.

Nwosa, P. I., and Oseni, I. O. (2011). Efficient Market Hypothesis and Nigerian Stock Market. Research Journal of Finance and Accounting, 2(12): 38-46.

Olabisi, P. R., Jeremiah, E. O., Phillip, A. O., Omobola, A., and Ademola, O. A. (2017). Stock Market and Economic Growth in Nigeria. International Journal of English Literature and Social Sciences, 2(6): 97106.

Owido, P. K., Onyuma, S. O., and Owuor, G. (2013). A GARCH Approach to Measuring Efficiency: A Case Study of Nairobi Securities Exchange. Research Journal of Finance and Accounting, 4(4): 1-16.

Pervez, M., Rashid, M. H., Chowdhury, M. A., and Rahaman, M. (2018). Predicting the Stock Market Efficiency in Weak Form: A Study on Dhaka Stock Exchange. International Journal of Economics and Financial Issues, 8(5): 88-95.

Sania, S., and Rizwan, M. (2014). Testing Weak Form Efficiency of Capital Markets: A case of Pakistan. International Journal of Research Studies in Management, 3(1): 65-73. 